\title{
Implementing Professional Approach within a Translation Course to Sharpen the Student/Translator's Practical Skills for Demands of the Labor Market
}

\author{
Nagwa ElShafei \\ Mansoura University \\ E-mail: nona6600@hotmail.com
}

Received: 03-11-2013

doi:10.7575/aiac.ijalel.v.3n.2p.145
Accepted: 13-12-2013

Published: 01-03-2014

URL: http://dx.doi.org/10.7575/aiac.ijalel.v.3n.2p.145

\begin{abstract}
The recent and fast development in various spheres of information and communication technology, global trade, digital and social media have resulted in growth in excellent employment opportunities but also influenced the labor market. For instance, some jobs have become absolute, while others, related to information technology particularly, have become in higher demand. As such, there are many scenarios in which translators find themselves unable to communicate with their clients due to cultural and language barriers, especially in labor market environment. This clarifies the great need for translators to receive professional training which also takes into account the advancement in technology. Therefore, market demands should be taken into account when developing and planning university courses and curricula to meet the job market needs. Courses on translation and interpretation prepare professional translators as needed by the labor market. In other words, the role of academic professional and curriculum planners should be narrowing the gap between what the labor market needs from the modern translator and the courses offered by training institutions, universities and colleges. This research study introduces a Professional Approach to teacher to educate translators within the faculty of arts, in a manner that fits the requirements of the job market. As such, a unit was prepared and specified for the students, then taught by the researcher to the selected sample. The dependent t-test technique was employed to compare the means of the total scores of the experimental group on the proficiency pre-post administration of the tests. It was noted from the results that there is a notable difference between the mean scores of the two groups in favor of the experimental group.
\end{abstract}

Keywords: Professional Approach, translation course, student translator, practical skills, labor market demands.

1. Introduction

\subsection{The Problem}

Students in the Faculties of Arts use translation professionally in their work after graduation. They need to be able to conduct professional translation practice throughout their school and work activities (Massoud, 1987) and also to learn technical and academic writing (Warby, 1999). In addition, they need to develop skills required to complete the various stages of translation (Catford, 1965) \& (Koltaly, 1999). The technical communication courses should include more attention to translation as a fundamental component of the course assignment and project practice (Hornby, 1992). Consequently, the students need to practice translation skills (Elshafei, 2010) to better prepare them for post-graduation job opportunities (Maylath, 1999) \& (Frievalds, 1999) As such, we propose the following as the most important criterion for professional translation practice as suggested by Farahzad (1992):

1- Accuracy

2- Appropriateness

3- Naturalness

4- Cohesion

5- Style of discourse and word selection

These are the main principles used to judge different stages of translation (Najeeb, 1995) such as the receptive (listens reads) \& productive stages (speaks - writes). Meanwhile, Mouriello (1992) divides stages of translation into mainly two: 1) passive stage (listens - reads), and 2) active stage (speaks - writes). From this classification, it appears that the student translator usually practices listening and reading skills during the first stage and speaking and writing during the second one. These main skills include sub- skills as: skimming, scanning, summarizing, note-taking, note making, using dictionary, writing main ideas and revising (Baker, 2005) which are also needed after graduation (Newmark, 1991). Referring to required translation skills, Slype (1983) suggests the following list:

1- $\quad$ Adequate analysis skill

2- Expressive skill of emotions and feelings 
3- Word selection skill

4- Effective writing of first language

5- Effective writing of second language

6- Neutral attitude to both languages

7- Selecting proper alternatives

8- Good revising and editing

\subsection{Importance of the Problem}

1- Help teachers of translation at university stage recognize the translation skills required for students before and after graduation that prepare them for labor market

2- Help students recognize translation skills which improve their translation production for labor market

3- Guide course designers to avoid the separation between the course content, students' needs, and the job demands.

\subsection{Relevant Scholarship:}

Some studies (Ali, 1986\& 1991 and El Shoura,1994) discussed translation errors extensively. They analyzed students' errors in written translation at university stage. The results revealed various types of errors in students' translation. They are mainly grammatical, lexical, and semantic errors. It has also been found that the students lacked the ability to translate well because of the improper translation courses they completed which lacked adequate practice. Mouriello (1992) lists some of the common errors in translation such as nonsense, over-translation, misunderstanding, undertranslation, and mistranslation, omission of tenses and word, problems with structure form, grammar and style, as well as issues with topology.

These points and those of previous studies revealed weakness in students' translation and in turn affect the quality of their preparation for labor market resulting from the lack of well-designed courses of translation. This urged many researchers to construct and propose programs and courses in translation to help students improve their level before and after graduation. Other studies discussed translation courses \& curricula as (Cote, 1990) who designed a translation course for higher education students at the American University in Cairo. The results showed the improvement of students' proficiency in translation from and into English that indicated their competency to work for labor market.

Another study (Patmon, 1994) investigated and demonstrated the improvement of students' performance on language and translation as a result of the course selection that prepare students to work for labor market. As such, it appears that training and course programs with proper contents usually result in considerably good results. They not only result in improved student achievement and proficiency in translation but also the development of their language and communication skills (Elshafei, 2011). In 2000, Beaurgrande came to the conclusion that translation is best defined as the practical use of language. It is a testing device to measure students' linguistic competencies as well as their ability to fit into the dynamic needs of the job market.

In spite of the vital role played by the translation programs in improving students' skills, few studies have been conducted in the area of applying the Professional Approach, to the best of our knowledge. Among these studies is Higgazy (1994) who conducted a survey to investigate some problems of faculties of Specific Education. The results showed the lack of well-designed courses, poor performance of students and hence the improper preparation for the labor market. MofeedShihap (Shihap, 2003) recommended (in Specific Education conference at Cairo) that graduate courses need to be evaluated and constructed to meet the students' needs and demands of the labor market. Also, it stated that the traditional preparation of students with poor courses has not been sufficient to produce a creative and qualified graduate in different fields. Hussien (1999) came to the conclusion that the proper activities and tasks should be included in second-language courses in order to help students develop their language and translation skills as needed by the labor market.

Based on the researcher's teaching experiences at faculty of Arts, correcting students' answer sheets and interviewing teachers and students (at Taif), the following points were indicated. One of these points was the dissatisfaction of both teachers and students with the contents introduced which lack the Professional Approach items. Another point was the low standard of students and accordingly their bad performance after graduation. An additional point was the unsuitability of the preparation at the university. All points were attributed to the gap between the academic preparation at the university and the real work in labor market. That is known as the Professional Approach term, used in academic fields to correlate learning with work.

\section{The Definition of the Professional Approach}

The Professional Approach, as a term, means a comprehensive, sustainable, and intensive approach used by instructors in order to improve students' skills required for the labor market. In other words, it is supposed to develop students' performance to satisfy the job requirements (Gabr, 2001). It also facilitates more accurate and progressive assessment of the student's development in practical translation work. This is primarily because teachers can assess the final translation work as well as all other stages in the translation process. The ultimate objective of integrating the Professional Approach items into translation courses is to prepare the student for the rigorous requirements of the job market. In addition, it is used to expose students to the potential future working conditions(Olvera, 2005). Meanwhile, this approach is such an attempt to improve the training process and is not necessarily what is all required. 
Further studies tackled applying the Professional Approach as well as correlating translation courses with labor market requirements (Olvera, 2005). This study introduced a course - within the University of Granda, Spain, which included homework assignments in translation. These tasks presented topics that tackle real- life issues. This helped students recognize their future employment world, which is known as Professional Approach for Translator Training. The main purpose of delivering that program is to improve students' translation aptitude and enhance their experience in a serious attempt to prepare them for the competitive job market. It generally enhances the student's professional career track, as well.

The Professional Approach not only focuses on meeting job market requirements, but also makes students aware of the ties among four-year degree program courses and the actual practice of translation and interpreting and which are essential part of the syllabus. In sum, through the application of the Professional Approach to translation training programs, and given its practical exposure to 'real-life work' within training courses and assignments, the following key milestones can be achieved:

- Motivation and commitment of the learners to the learning process and professionalism

- Effective methodology, prioritization skills, ordering of objectives, and material depth specifically made for students' needs, both individually and collectively with practical training

- $\quad$ Accurate and sustainable approach oriented toward progressive improvement

- Adequate balance between theory and practice with emphasis on the practical application of theory embedded in exercises

- $\quad$ Suitable parallelism between visual simulation of 'real-world' activities and practical activities in order to improve skills and application of theory

- Effective reinforcement facilitative of independent student work during class and during outside and extracurricular activities

- $\quad$ Efficient exploitation of pedagogical contexts, technology and diverse media in training

- Noticeable application of each course within the program in institutional, social, and professional domains

Another study (Gabr, 2001) was conducted to further investigate this matter. It analyzed the method of developing and designing training program and their application within the undergraduate curriculum of the Department of English, Faculty of Arts, at Ain Shams University (founded in July 1950). The questionnaire and interview utilized in the study to collect data from a chosen sample. Upon verifying the methodology validity and integrity, the questionnaire sheet was presented to a diverse and random sample of 100 students, out of the entire cohort of $400,4^{\text {th }}$ year students. The following can be concluded from the interview results:

1. Teachers of translation are mainly of academic and educational backgrounds with no professional and practical experience in translation work

2. Most teachers haven't received any formal education in translation

3. The method of developing the activities and material of the training programs were almost prepared randomly

4. The infrastructure was very weak and facilities were not adequate for training. This weakened the effectiveness of teacher's ability to conduct their classes

5. The program did not emphasize group and collaborative work

The above observations resulted in a weak and nearly ineffective program altogether. Anthony Pym (2001) reviewed and presented various programs for training translation teachers which were utilized in Tarragona/Spain, Rennes/France) and Monterey/US. The surveyed teachers met the international demand as a result of the newly-created translator training programs in many countries recently. These programs can be classified as experimental to one degree or another and were considered as success. The workshops and project that followed these programs are also outlined. The details and content of the program activities and assessments of their seminars were also established at the University of Rovira i Virgili in Tarragona, Spain. Potential practical collaborative work was also assessed.

A study implemented by Afnan Fatani (2006) discussed the results of a market research study at King Abdul-Aziz University in Jeddah. The goal was to clarify the considerable gap between training programs Saudi universities. It also reviewed and analyzed the requirements of professional career, as demanded by most recent job posting description in an attempt to elaborate how language technology can be integrated effectively into the translation curricula. This aims to align student skills with the requirements of the dynamic professional environment.

In addition, it discussed the factors inhibiting the use of translation technology tools, such as e-translation, within the Saudi labor market. It further highlighted the cultural factors hindering the integration of such tools into the translation curriculum, not just universities but also at work and governmental agencies. Furthermore, the results emphasized the lexical and syntactic errors as a result of using dictionary-based strategies in translation. Also, it discussed the lack of applying more communicative strategy. In addition, it has revealed the ineffectiveness English Departments' efforts in all Saudi universities to improve the language aptitude of their students, which is most needed by the Saudi and international job market.

A study by Reima Al-Jarf (2006)at King Saud University with the title 'Unemployed Female Translators in Saudi Arabia: Causes and Solutions.' was conducted to study the conditions of male and female translators in the Kingdom. It shockingly concluded that $90 \%$ of female Saudi translators who graduated between 1990 and 1996 were not practice their education at all. Further to our surprise, out of the 130 female translator interviewed, and who were graduates of 
the cohorts 1991 to 1996 , only 13 were found to work as translators. This is very disappointing and further reveals the weakness and impracticality of translation training in Saudi universities which results in the filling of such jobs by foreign translations.

A brief review and study of machine-based translation in Saudi Arabia (Sieny,2006) highlighted theusage of translation technology very frequently in Saudi institutions as dictated by the needs of the labor market since the 1980s. Another study (Sheal, 1989) determined the correlation between translator training and the prevalent market needs in details. It provided interesting and practical recommendations to close the gap between the two. According to Sheal, the following phases should be taken into account when developing the curriculum:

\section{1) Market Need Identification}

To design a successful training program for translators, the job market should be definitely taken into account, seriously. Sheal argues that 'the market for translation is completely interfaced by available technology,' and therefore, the professional translator 'should physically possess basic computer technology,' not only to be able to work with geographically distant clients, but also to have wider access to various databases. Hence, translators cannot survive as professional translators without the effective utilization of such tools. In addition to addressing the use of basic electronic tools, translator training programs should integrate more vocational practice and less academic training, on the other hand. An adequate translation program should cover certain aspects of the actual profession itself to give the student a clear idea of post-graduation expectations with exposure to hands on duties.

2) Student Need Identification

Stern and Payment (1995) assured that ignoring the needs of the students will eventually void any serious training effort. The consequences may include the following:

- Undesirable course material and activities

- Loss of connection between teachers and students

- Simple material that is not sufficient to prepare the future translator

- The teacher loses their confidence and performs poorly

Therefore, the course should definitely integrate both the broad objectives of the curriculum and the personal needs of the students.

3) Educating Students for a Dynamic Job Market

The job market has changed dramatically over the last couple of decades. This resulted in the diversification of international training programs with the introduction of comprehensive courses on legal, commercial, financial, subtitling, multimedia, localization, translation as well as advanced utilization of voice recognition systems. This makes the training programs more specific and challenging, therefore. The job market will also be looking for specialized translators, as such. The students have to be trained to become translators, terminologists, technical writers, language engineers, project managers, and much more. Gouadec argues "Translators should be trained at university, not simply taught at university, and then trained on the job. This is because the university is the only place where people have the time and willingness to insist on proper methodologies and strategies whereas on-the-job activities are much too sensitive to the pressures of time-to-market, productivity, and economic survival. It is essential that anyone entering the job market be properly armed to withstand unreasonable influences."

Effectively training institutionstypically utilize technology (students' workbenches, software packages, specialist teachers, maintenance crews, etc.) to prepare the students adequately for future employment which required the knowledge of such applications. The following translation technologies are essential in anyprogram: terminology, electronic tools (i.e. workbenches and Translation Memories), and market-coaching on how to get clients and contracts, to set up business, to find jobs, to conduct project and cost estimate. An informative and highly relevant translation memory survey was implementedby Alan Wheatley, as a partial fulfillment of a mandate by a new EU-funded project under the Leonardo da Vinci IIprogram. The project mandate promised to create a freely accessible repository of data and material and tools to be utilized by international training programs and translators. Wheatley's survey is important as it extensively identifies the factors which may inhibit the use of TM or TT tools, as well as views on training in the use of translation tools and methodologies.Although conducted in England and other EU countries, the findings are deemed universal and can accurately apply to the Saudi market and other Middle Eastern countries.This figure by Gabr (2001) concludes the Professional Approach followed in the previous studies.

Pre-Development Stage-- Identify Market Needs: Identify Student Needs: Select Student and Course Evaluation Instruments: Define objectives: Conduct Training Design Student ------and Course Evaluation Instruments

Development Stage Prepare material Select Teaching Methods \& Techniques Develop Lesson Plan 


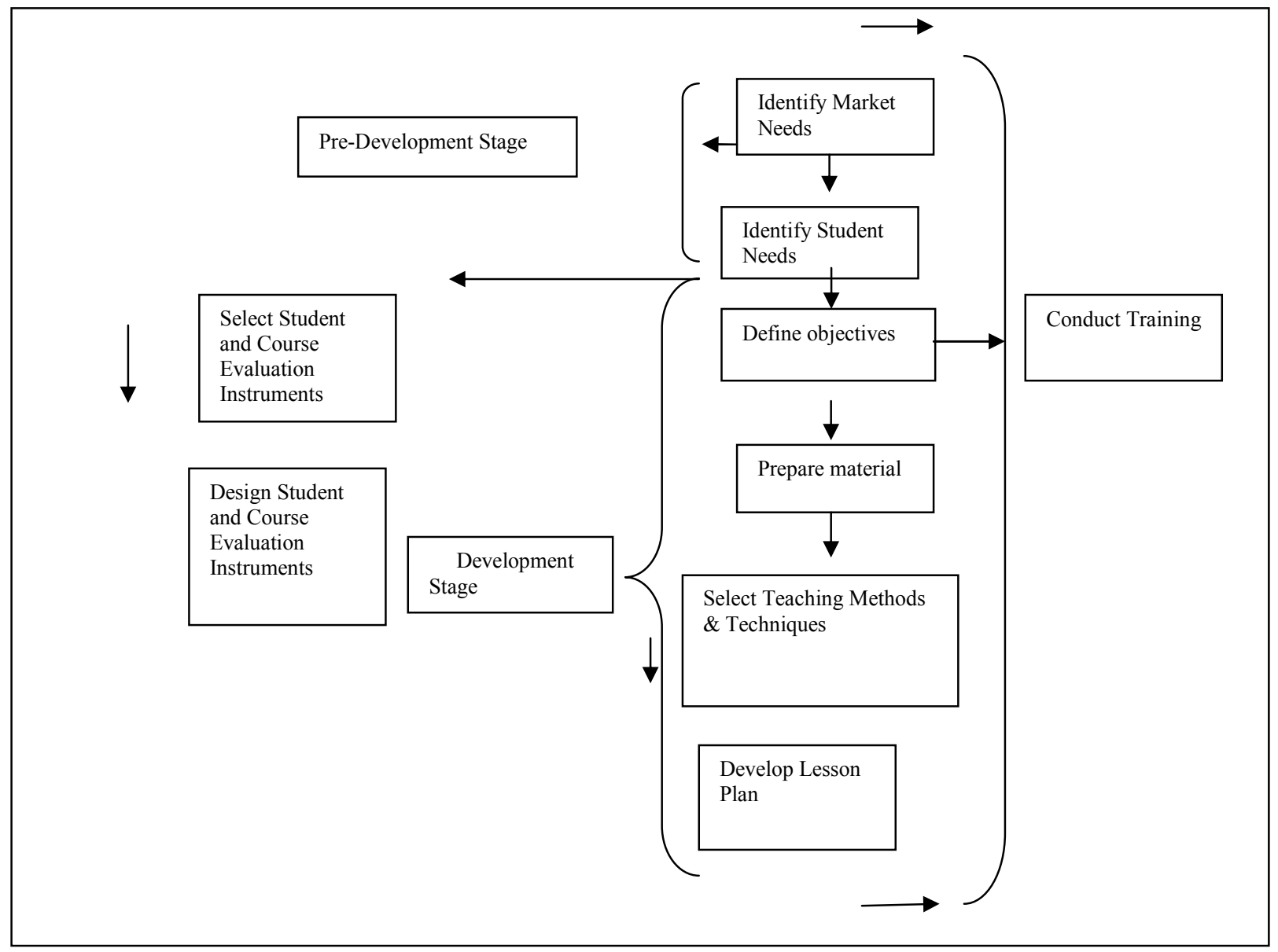

As shown above, Gabr (2001) used a framework offered by Professional Translation to establish than effective translator training program. The initial phase is to identify market needs, then the determination of students' needs, as previously highlighted. This is all needed for developing a translator program. The Professional Approach is therefore, based on concrete basis. According to the Professional Approach, from the very moment translators receive a translation brief until the completion of the translation piece, they must conduct a series of activities and duties which can be distinctly divided into four stages: 1) documentation, both the source and the target languages, 2) terminology, 3) translation, and 4) revision, edition, and desktop publishing. We, therefore conclude the following:

- Applying the Professional Approach in the English language courses is not very well described and explained for application in university education (Fatani, 2006)

- There is a serious need to develop university-level courses that can meet the labor market's needs (Sheal, 2006)

- $\quad$ The proposed courses, if develop adequately, should meet students' needs as well as the job requirements post-graduation (AlJarif, 2006)

The above findings encouraged the researcher to propose a program to sharpen students' skills for labor market as will be discussed next.

\subsection{Hypotheses}

The present study sought to test the following hypotheses:

1- $\quad$ A statistically significant difference exists between the mean scores of the experimental students before and after the administration of the proficiency test in favor of the post administrations

2- $\quad$ No statistically significant difference existed between the mean scores of the control students on both before and after the administration of the proficiency test

\section{Method}

\subsection{The Pilot Study}

A pilot study project was conducted in the form of an open-ended questionnaire delivered to fifty 4th year students studying English at the faculty of Arts and later to thirty professors within the same department of Taif University. The questionnaire, which was prepared by the researcher, was given to students before graduation. This aims to assess and determine their needs when designing the proposed program. Another questionnaire was given to translators while on the job after graduation working in different institutions to gauge the work requirements as indicated by the translator. This questionnaire is also prepared by the researcher to identify the importance and the need of translation as a 
profession. The sample students are from the Department of English at the Faculty of Arts. A Professional Approach was integrated into the class, which was taken by all surveyed students.

During the study, the students were asked about the importance of translation to them during and after studying. Most of the students indicated that they were interested in getting relevant and well-paid jobs while working for different institutions. They also showed interest in working abroad to translate various books and perhaps going back to school for graduate studies. Another question was asked about the activities of translation within the Professional Approach. As a result, the student indicated activities that helped them translate interestingly, communicatively, with use of various media and presentation methods with emphasis on the correct use of acronyms and attention to verbal dialogue. The students also reports work duties of translation within various areas such as commercial, medical, religious, educational and political domains.

An additional question was asked about the skills required to get the work done to a satisfactory level with the following answers gathered:

- To translate documents accurately

- To use dictionaries and tools effectively

- $\quad$ To speak fast and fluently

- To edit various incremental versions efficiently

- To work on machine translation

- To write the abbreviation correctly

- To write Arabic and English accurately

In an open ended question, the instructors were requested to determine the reasons behind difficulties faced at work, with the following answers indicated:

1-Lack of relevant courses

2-Lack of effective teaching

3-Lack of needed translation skills

4-Lack of workshops

5-Lack of practicing simultaneous translation

6-Lack of practicing oral translation

These findings indicated the problems faced by students while translating before and after graduation especially during work. The results also indicated that most of those problems can be attributed to weakness in translation they completed during their studies. Those courses did not provide sufficient time for carrying out workshops or practicing oral translation assignments which are essential for all those who are involved in the translation process. Within the questionnaire, the instructors were also asked to give their suggestions concerning suitable unit and items of the Professional Approach within their courses. They highlighted the following features to be useful for any course they would take:

1-A course based on topics related to labor market

2-A course including specific skills for work after graduation

3-A course suiting the students' needs

4-A course based on the views of the subject specialist

5-A course based on the views of the English language specialists and people working in labor market

Thus, the results of the pilot study indicated the translation skills needed in their study at the university and work place and that the translation courses presented to them did not fully address these skills.

\subsection{Participants (subject) characteristics}

The sample consisted of the students enrolled within the English Section, Faculty of Arts of Taif University. $4^{\text {th }}$ year students.

\subsection{Sampling Procedures}

The participants were sampled as they were more educated and hence can give more concise feedback; these students have already attended more translation classes and as a result can assess the situation more objectively. As well, they have already studied different types of translation, including media topics, writing documents, technical writing, academic writing, communication skills, etc. As a result they were able to follow instructions easily.

\subsubsection{Sample Size, Power, and Precision}

The sample consisted of sixty girls enrolled in English section, faculty of Arts,

Saudi Arabia. In addition, they are the cohort that is just about to graduate and can hence reflect more on their thought of what the job market may need.

The Professional Approach unit was applied to the commerce field as it has been chosen and encouraged by most of the jury members as a more needed and practiced field of translation nowadays. Also, this field has a common factor in 
using some features, with other fields such as educational, political, medical, religious, banking, journalistic and economic.

\subsubsection{Measures and Covariates}

1- $\quad$ A questionnaire prepared by the researcher for English language and translation specialists to identify their views regarding students' needs, translation skills, and the most important topics and the items that should be included in the Professional Approach unit

2- $\quad$ A translation proficiency test prepared by the researcher

\section{These research questions were asked to decide the research limits:}

What is the efficiency of a translation unit including items to apply the Professional Approach on sharpening translation skills required to labor market within the Faculty of Arts? The question was then divided into the following sub-questions:

1- What are the most important translation skills necessary for students/translators?

2- What are the most important fields and subject matters related to students' specialization after graduation?

3- What are the main content elements of the unit included within the Professional Approach? And to what extent such units are efficient in sharpening the skills necessary for the work?

\subsubsection{Research Design}

\subsubsection{Problem of the Study}

By revising the previous studies and the researcher's experience in teaching at the Faculty of Arts, besides the above pilot study results, it has been noticed that students lack practical translation skills required for work. Also, some problems were noticed such as the lack of professionalism and standards in translation which resulted in poor translation work, which is why we decided to pursue this study in the first place.

\subsubsection{The Purpose of the Study}

This study aimed at achieving the following points:

A . Identify the translation skills required in labor market.

B .Construct a translation unit including items for applying the Professional Approach specifically within the commerce field.

Assessing the efficiency of the teaching unit in sharpening the identified proficiency skills in translation The study proceeded as follows:

1- Extensive literature was reviewed with special reference to translation courses and the application of the Professional Approach

2- A need analysis questionnaire was constructed, validated, and administered to thirty English language and content area specialists. The purpose was to identify their views regarding students' needs of learning translation, the skills of translation related to Professional Approach that are necessary for the target population at the university and work place, and the most important fields and subject matters to be included in the unit

3- The needed translation skills for labor market and job requirements were determined in the light of the review of literature and the feedback obtained from the specialists' questionnaire. Accordingly, the unit general objectives were formulated and the translation fields and their related topics were determined

4- The syllabus of the unit was designed based on the results of the two questionnaires and the pilot study

5- To gauge the effectiveness of the proposed unit, the following were carried out:

a- Planned the lessons of the unit to be taught

b- Submitted the unit components (objectives, the developed lessons of the course, and proficiency test) to a group of jurors (English language, and translation specialists) for validation

c- Administered the proficiency pre-test to measure students' actual level before having any instruction

d- Taught the unit to the students

e- Administered the proficiency post-test, the same form of the pre-test, after instruction was over

f- Completed score gathering, and applied statistical treatment and analysis to the pre-post proficiency test' results using the statistical technique of dependent T-test

g- Discussed and deduced results, conclusions, and recommendations accordingly

\subsubsection{Experimental Manipulations or Interventions}

The researcher used the quasi-experimental methodology to assess the efficiency of the translation unit. The independent variable would be represented in the unit, while the dependent variable would be represented in the development of proficiency skills in translation.

\section{Results}

\subsection{Recruitment}

In this section, the findings of the experimental study are discussed and analyzed. We want to determine the impact of inserting the Professional Approach unit into translation course on improving student/Translator's skills for labor market. To fulfill this requirement, the unit was prepared and specified for the students then taught by the researcher to the selected sample. 


\subsection{Statistics and Data Analysis}

The dependent t-test technique was employed to compare the means of the total scores of the experimental group on the proficiency pre-post administration of the tests. The results showing the difference between the mean scores are presented in the following two tables:

Table 1. Overall Results of the Proficiency Test: $(\mathrm{N}=60)$ (Per-Post Administration) of the experimental group.

\begin{tabular}{ccccl}
\hline Test & Means & SD & t-Values & $\begin{array}{l}\text { Level of } \\
\text { Significance }\end{array}$ \\
\hline Proficiency pre-administration of the test & 7,24 & 21,20 & 5.19 & .01 \\
Proficiency post-administration of the test & 22,54 & 8,03 & & \\
\hline
\end{tabular}

It is noted from the previous table that there are differences between mean scores which refer to a significant change for the benefits of students' post performance. The obtained T-value for the proficiency test is $5.19 \%$ that is significant at level of 0.01 .

Overall Results of the Proficiency Test: $(\mathrm{N}=60)$ (Per-Post Administration) of the experimental group. Test Means SD tValues Level of Significance Proficiency pre-administration of the test Proficiency post-administration of the test 7,24 22,54 21,20 8,03 5.19.01 It is noted from the previous table that there are differences between mean scores which refer to a significant change for the benefits of students' post performance. The obtained T-value for the proficiency test is 5.19 that is significant at level of 0.01 .

Table 2.Overall Results of the Proficiency Test: ( $N=60)$ (Per-Post Administrations) of the control group.

\begin{tabular}{lcccl}
\hline \multicolumn{1}{c}{ Test } & Means & SD & t-Values & $\begin{array}{l}\text { Level of } \\
\text { Significance }\end{array}$ \\
\hline $\begin{array}{l}\text { Proficiency pre-administration of the test } \\
\text { Proficiency post-administration of the }\end{array}$ & 6,37 & 11.12 & 0,308 & Non-significant \\
test & & 4,05 & & \\
\hline
\end{tabular}

Overall Results of the Proficiency Test: $(\mathrm{N}=60)$ (Per-Post Administrations) of the control group. Test Means SD tValues Level of Significance Proficiency pre-administration of the test Proficiency post-administration of the test 6,37 $8,2511.124,050,308$ Non-significant It is noted from the previous table that there are not differences between mean scores which refer to a non- significant change for the benefits of students' post performance. The obtained T-value for the proficiency test is 308 that is non-significant.

As is clear from the two tables above, the differences between the mean scores show a significant improvement in favor of the students' post-performance. The obtained t-value for the proficiency test is 5.19. Both are significant at the level of 0.01 . Hence, it can be inferred from the findings of the previous two tables that the two hypotheses of the present study have been accepted:

1. The existence of a statistically significant difference between the mean scores of the students' performance on all the items of the proficiency test compared to the mean scores on the same items of the proficiency test postadministration in favor of the proficiency post-one among the experimental group.

2. There is not a statistically significant difference between the mean scores of the students' performance on all the items of the proficiency test in pre-administration and their mean scores on the same items of the proficiency test on the post-administration among the control group. This means that the unit that was applied was efficient and this might be taken as an indication of the efficiency of the whole unit including the Professional Approach items. There were inter rater reliability that showed over 95 correlation (or $\mathrm{p}<.001$ ), indicating very high consistency in raters' use of the same criteria in correction.

\section{Discussion}

In the following brief commentary on the above, the researcher will show the similarities and differences between these studies and the present one. Like Fatani (2006), the present study clarified the differences in effectiveness between these courses including professional approach and those free from such approach that help in preparing students for Labor Market, but instead of using translation technology, the present study used printed material. Like Al Jarf (2006), the present study revealed the weaknesses and impracticality of translation at university stage, but instead of applying survey study, the present study implemented a practical one. Like Olevera (2005), the present study delivered professional approach to students/translators at university stage, but instead of using homework and class activities to train the students on it, the present study introduced it through a certain course. Like Gabr (2001), the present study involved the professional approach into the translation course, but instead of implementing an interview to collect information, the present study applied a translation test. 
Like Patmon (1994), the present study investigated the students' preparation for Labor Market, but instead of developing students' performance, the present study developed students' proficiency. Like Cote (1990), the present study designed translation course to improve students' translation skills, but instead of designing only a course, it inserted the professional approach into the course.

\section{Conclusions and Recommendations}

The following conclusions could be extracted: the successful approach leads to effective learning. Also, the inserted approach improved the students' proficiency in translation before and after graduation. In addition, students' motivation and participation are maintained if the teaching materials presented to them are relevant to their field of specialization and work after graduation. Furthermore, learning can be far more effective if was based upon the students' needs and previous experiences.

Based on the results and conclusions of this study, we offer the following recommendations:

1- The Professional Approach unit, inserted in the translation course, added more value to students at the Faculty of Arts. It is recommended that this approach be utilized with other branches of translation because of its effectiveness

2- The present study improved learning outcomes after graduation. Thus it is recommended that more attention should be given to the state and conditions of translation curriculum in university

3- Co-operative learning is recommended. This made activities look real and encouraged students to interact with each other

4- Variety in activities is useful for students to be ready for the dynamic needs of the job market

5- The development of both Arabic and English translation skills is needed for job demands

6- Providing extra-curricular workshops creates a healthy atmosphere for practicing different types of translations.

7- Practicing group work, as tested in the present study, also helped students to develop effective translation skills

8- Teaching staff should have a broad background and knowledge of the labor market demands

\subsection{Suggestions}

The present study poses the following points to be considered for further research:

1- This study applied Professional Approach on commercial translation. It may be necessary to apply it to other fields to test its effectiveness in a more comprehensive manner

2- The present study dealt with pair work in translation classes so it might be needed to study the use of workshops in training students in translation further

3- This study focused on training students before graduation. It might be useful to measure their training after graduation in another study

4- The study used written translation with Professional Approach in the unit which improved students' proficiency in written translation. As a result, there is a need to a study investigates the effectiveness of applying Professional Approach for oral translation on developing pronunciation and speed

5- The present study applied a questionnaire to students to investigate their needs for job demands. There remains a need to a study to measure the need of people working on job before designing translation courses

\section{Acknowledgements}

I am grateful to all professors who encouraged me to carry out my research. I also owe debt to my colleagues and my students to let me the opportunity to implement such a study. Special thanks to my father, mother, and sisters who supported me throughout this work. Last but not least I acknowledge a personal debt to my family for their patience and continual help.

\section{References}

Al-Jarf, R. (In:Fatani,2006)`Unemployed Female Translators in Saudi Arabia: Causes and Solutions. Unpublished study, King Saud University, Saudi Arabia.

Aly, M.A.S. (1990). A suggested course in translation for students in English Section, At the Faculties of Education.

Baker, M. (ed.) (2005). Routledge Encyclopedia of Translation Studies. London: Routledge.

Beougrande, R. (2000) Translation in the university: prospects for the new millennium. http:beaugrande.Bizland.com/Translation \%20 in \%20 the \%20 universityS.htm (2000)

Catford, J. C. (1965). A Linguistic Theory of Translation: An Essay in Applied Linguistics. London: Oxford University Press.

Cote, P. (1990). From principles to pragmatic teaching Translation in the classroom. French Review, vol. 63, No. 3, Feb.

Elshafei, N. I. (2010) Expressive Language in The Holy Quran improves the Translator's Literary Arabic Version.Journal of Educational Research -Munufiya University, V.25, part3.

El-Shimy, A. M. N. (1997) A suggested course of English language for the Home Economics Students at the facilities of Specific Education. Unpublished M. A thesis, Faculty of Education, Zagazig University. 
El-Shoura, S.E. (1994). A study of the interlingual and the interalingual translation errors in English by general secondary school students. Unpublished M. A. thesis, Faculty of Education, Zagazig University.

Farahazd, F. (1992). Testing achievement in translation classes. In Dollerup \& Loddegard (Ed), Teaching translation and interpreting.

Fatani, A. (2006), Globalization and the Translation Industry in Saudi 4 Arabia: Factors Inhibiting the Use and Integration of Translation Technology into Mainstream Coursework. Unpublished study, King Abdul-Aziz University, Jeddah.

Freivalds, J. (1999). The technology of translation. Management Review, July / Aug 88(7), 48-52.

Gabr, M. (2001). A Missing Critical Link in Translation Training. Translation Journal, 36, 11-16.

Goffin, R. (1997). Translation in English language teaching. A case study file://A:/Dissertation Abstract. htm. returnto $\mathrm{El} / \mathrm{Home}$.

Hissein, H.E. (1999), A proposed programme for enhancing reading English in the field of specialization among educational -technology students at the Faculty of Specific Education and its effect on their attitudes towards reading. Unpublished Ph.D. thesis, Faculty of Education, Tanta University.

Hornby, M. (1992). The professional translator of tomorrow: language special or all- round expert? In Dollerup \& Loddegaard (ED), Teaching Translation and interpreting, Prentice Hall, London.

Koltaly, T. (1999) Writing globally. Journal of Business \& Technical Communication, vol. 13, No. 1, p. 86.

Massoud, F. M. (1987) Translate to communicate. David C. cook foundation.

Maylath, B. (1999). Writing globally: teaching the technical writing student to prepare documents for translation. Journal of Business \& Technical Communication, vol. 11 (3) pp. $339-352$.

Mouriello, G. (1992) Teacher's tools in translation class. In Dollerup \& loddegaard (Ed)., Teaching translation and interpreting.

Newmark, P. (1991),2nd Ed. Approaches to Translation. London: Prentice Hall Press.

Olvera, Maria Dolores, \& etal (2005) Translator Training and Modern Market Demands, Perspectives : Studies in Translation.Vol.13, No.2.

Patmon, D. (1994) Teaching Japanese culture and values through Japanese literature in translation: the development of a model syllabus for and undergraduate college Students. DAI-A 56102, p. 556, Aug 1995.

Pym, A. (1992). Translation error analysis and the interface with language teaching. In Dollerup \& Loddegaard (Ed). Teaching translation and interpreting.

Pym, A. (2003),Trial, Error and Experimentation in the Training of Translation Teachers. Intercultural Studies Group, University of Rovira I Virgili, Tarragaona, Spain.

Sheal, P.R. (1990). How to Develop and Present Staff Training Courses, London: Kogan Page Limited.

Sieny, M. (1989). Machine Translation in Saudi Arabia. www.mt-archive.info/MTS-1989-Seiny.pdf

Warby, D. B. (1999) Suggestions for translating research into classroom practices. Intervention in school \& Chinic, vol. 34 (4) p. 205.

\section{Arabic References}

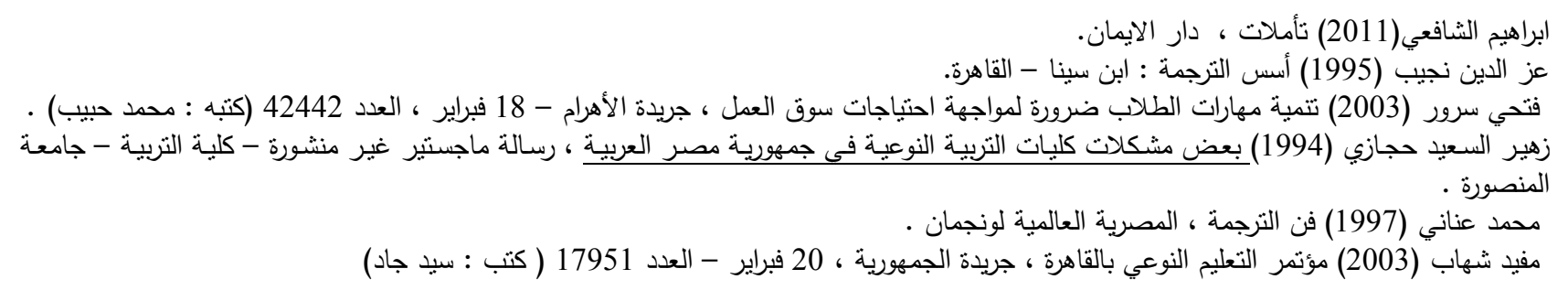

